\title{
Caribe: representación audiovisual del cine latinoamericano
}

\section{Caribe: Audio-visual representation of the Latin American cinema}

\author{
Leonardo Roque Pujol \\ Universidad Federada de Costa Rica San Judas Tadeo \\ leonardo@usanjudas.ac.cr \\ Fabiola Quiroz Condori \\ Universidad Federada de Costa Rica San Judas Tadeo \\ calidad@usanjudas.ac.cr
}

\begin{abstract}
Resumen
Este artículo se ubica en el tipo de estudio que analiza la producción cinematográfica desde la perspectiva semiológica y estructural de un producto audiovisual costarricense de acuerdo con las normas de producción y realización del cine latinoamericano. El estudio analiza la estructura narrativa, la construcción de los personajes, el manejo de los escenarios y la composición visual. El estudio adopta una metodología cualitativa con alcance analítico. Los resultados ubican el film Caribe como una obra nacional que responde a una organización de la producción y realización consecuente con el cine latinoamericano
\end{abstract}

Palabras claves: film, cine latinoamericano, cine costarricense

\begin{abstract}
This research article analyzes the cinematographic production from the semiotic and structural perspective of a Costa Rican audiovisual product. The study analyzes the narrative structure, character building, stage setup, and visual composition. The study also adopts a qualitative methodology with an analytical scope. Results locate the Caribe film as a national product, produced by an organized production and good study of the Latin American cinema.
\end{abstract}

Keywords: film, Latin American film, Costa Rican film 


\section{Justificación}

$\mathbf{E}$ 1 objetivo de la investigación es poner bajo la lupa crítica un film que trascendió el tipo de obra común en el cine costarricense. El análisis se enfocará en el tratamiento de los rasgos cinematográficos de la obra que la identifiquen como un producto del cine latinoamericano.

Entre los años 2000 y 2017, Costa Rica produce 60 largometrajes debido al apoyo hecho al sector audiovisual por diferentes organizaciones. Entre las organizaciones que apoyaron la producción audiovisual nacional se encuentran CINERGIA (2004) y el Programa Nacional para las Artes Escénicas (2007).

Caribe es un Film costarricense del director Esteban Ramírez que se estrenó en el año 2004 y que alcanzó la cifra record de 80000 espectadores en el país. Ganó varios premios nacionales e internacionales relacionados con el medio ambiente y la naturaleza.

El guion surge de una adaptación hecha a un relato del escritor costarricense Carlos Salazar Herrera por el propio director Esteban Ramírez. El argumento gira alrededor de un triángulo amoroso, la llegada de una trasnacional petrolera que quiere perforar en la zona y la respuesta de los habitantes ante los hechos.

Un medio de comunicación nacional publicó "La película contribuyó a una toma de conciencia dentro y fuera de la nación sobre la riqueza y diversidad natural y cultural como la principal ventaja comparativa de Costa Rica".

1 Mi Butaca.VIP. http://www.mibutacavip.com/cms. php?id_cms $=80$
La intención de esta investigación es rendirle el tributo adecuado a la obra ya que fue producida con altos estándares de calidad. Es una película que reúne las condiciones elementales para ser sometida a un análisis estructural y semiológico utilizando referentes teóricos con el fin de encontrar en ella los elementos que definen la producción de obras audiovisuales de género ficción en América Latina.

\section{Alcances y límites de la investigación}

El objetivo general de este estudio fue analizar los elementos cinematográficos del film Caribe relacionados con el tratamiento audiovisual de ficción en Latinoamérica.

Entre los objetivos específicos desarrollados están describir la estructura narrativa del film, identificar las relaciones de la dramaturgia del film con los procesos sociohistóricos, distinguir los vínculos que se establecen en la narración entre lo histórico o lo documental, identificar los aspectos relevantes en la composición visual que determinan una estética propia de acuerdo con el manejo escénico, y reconocer en la organización de la producción los elementos que evidencien economía de recursos y buena utilización del lenguaje audiovisual.

El análisis de la dramaturgia del film se realizará tomando como punto de partida la construcción de los personajes, su conflicto y su evolución en relación con el contexto y la época en que se desarrolla la historia.

Desde el punto de vista narrativo, se tomará en cuenta la estructura sintáctica de la obra y sus vínculos directos o indirectos 
con procesos históricos o circunstanciales. Las estructuras narrativas por evaluar están relacionadas con las secuencias y las escenas del film.

La composición visual estará en el orden de lo denotativo y lo connotativo, no entrando a analizar aspectos técnicos de la composición.

En la organización de la producción se tomará en cuenta la economía de recursos en la construcción del relato, como es el aprovechamiento de los escenarios y la utilización de las edificaciones.

\section{Metodología}

La investigación por desarrollar es exploratoria y descriptiva. Una investigación exploratoria ayuda a crear cierto grado de familiaridad con fenómenos desconocidos por su naturaleza o por su trascendencia teórica, además que ayudan a identificar conceptos y establecer prioridades para investigaciones posteriores.

Los estudios exploratorios se realizan cuando el objetivo es examinar un tema o problema de investigación poco estudiado o cuando la revisión de la bibliografía reveló que tan solo hay ideas vagamente relacionadas con el problema de estudio (Hernández, Fernández y Baptista, 2014).

Los estudios descriptivos buscan especificar las propiedades importantes de los fenómenos sometidos a análisis, en este caso el film, para entender el proceso de creación con la intención de describir o medir su significación dentro de un estilo y tratamiento cinematográficos específicos, como lo es el cine latinoamericano.
Los estudios descriptivos buscan especificar las propiedades, las características y los perfiles de cualquier fenómeno por investigar (Hernández et al, 2014).

Una investigación encaminada al análisis de un film irremediablemente está relacionada con la manera de analizar la forma y el contenido de la obra. Es imposible distanciar la historia contada de su estructura narrativa y de su interpretación. Delgado y Gutiérrez (2005) señalan que en un film las conexiones siempre son existentes entre el nivel sintáctico del texto y sus niveles semántico y pragmático.

La investigación tendrá un enfoque cualitativo que pretende relacionar procesos vinculados con la cultura, la narrativa y la propia utilización del signo audiovisual en el análisis del lenguaje audiovisual del film.

La investigación cualitativa permite establecer variables "no tan exactas" e identificarlas con conceptos o categorías esenciales para iniciar la investigación (Hernández et al, 2014).

Las investigaciones cualitativas se caracterizan por la invención que se traduce en dar cabida siempre a lo inesperado o por obturar toda rutina en el proceso de investigación (Delgado, 1995).

Analizar Caribe supone un proceso de búsqueda de indicios culturales arraigados a la forma de componer la imagen, la forma en que hablan, se visten y caminan los personajes por sus respectivos escenarios públicos y privados. 
La investigación cualitativa ha de concebirse como un procedimiento destinado a desestabilizar la inteligibilidad inmediata de la superficie textual mostrando aspectos no directamente visibles $y$, sin embargo, presentes (Delgado, 1995). No cabe duda de que la construcción de un nuevo discurso crítico paralelo a la historia se convertirá en la intención primaria de la connotación que se le haga al film.

Para la obtención de la información se estableció una metodología propia de la semiología interpretativa que abarca dos procesos básicos. El primero, estructuralista, relacionado con el orden de los elementos del discurso, y el segundo, de la semiótica textual, basado en una reconstrucción interpretativa del relato.

Se recurrió a un desglose de la obra audiovisual en términos de secuencias, escenas y planos para determinar la relación de su estructura con la intención semiológica de los espacios y elementos visuales.

\section{Análisis}

El contexto social que se establece en el film es la perforación petrolera en la zona del Caribe de Costa Rica a finales de los años 90 . En un 20\% de las secuencias del film, se aborda y se desarrolla en alguna medida el tema de la perforación, la corrupción y las posibles formas de comprometerse, como individuo o como sociedad, al respecto.

El film Caribe se desarrolla en la zona atlántica donde hay predominio de la raza negra sobre la blanca. Es importante resaltar que es una zona muy propensa a la migración de europeos y norteamericanos que buscan la playa y el sol en suelo costarricense.

Los personajes deben de tener tres dimensiones (Forero, 2002) para su credibilidad en el relato y que puedan justificar sus acciones: física, social y psicológica.

La construcción física y psicológica de los personajes no evidencia relación entre su pasado con los procesos sociohistóricos desarrollados en la obra. Vicente, Abigail e Irene no tienen rasgos que los comprometan con el Caribe. En la vida no desarrollada pero expuesta de los personajes, no encontramos indicios que establezcan relaciones de este tipo.

La edad y el aspecto físico de las mujeres son explotados para despertar el deseo de Vicente por ellas. La escena en la playa donde las hermanas se bañan, la escena de Irene en la cama, entre otras, descubren figurativamente la belleza de las hermanas, pero el tratamiento visual para describir las acciones no es el mejor. Carece de una focalización definida en función del protagonista o del espectador.

El ambientalista, quien juega un papel importante en algunas de las secuencias, sí muestra algunos rasgos físicos y otros de atributos (como es el bolso que carga) que lo identifican con la zona y sus habitantes.

El vecino de Vicente es el único de los personajes con importancia en la dramaturgia de la película que muestra rasgos caribeños, es decir, rasgos del negro limonense. Este personaje es poco explotado en todo sentido. No actúa como antagonista ni se 
identifica con sus acciones con alguna causa en el desenvolvimiento del conflicto en la obra. Es un personaje que solo figura frente a la cámara y aunque expresa argumentos interesantes, no afecta a otros personajes. El personaje está en contra de la perforación, pero sus expresiones lingüísticas y acciones físicas no responden en esa dirección. Es un personaje opaco en el film y evidencia su débil construcción.

El film no entra, como otras producciones costarricenses, en eventos de aspecto religioso.

Para Barroso (2005), existen tres tipos de personajes: los que se crean por repetición, por oposición y los que evolucionan y se transforman.

La construcción psicológica de Vicente es la más sólida en relación con el proceso que se desarrolla en el film. Aunque no es representativo de la cultura, es el personaje que se ve más afectado por el proceso social que se desarrolla, es decir, el problema de una eventual perforación petrolera. Es el único personaje que evoluciona con el conflicto social directamente. Las hermanas, Abigail e Irene, solamente reaccionan por conflictos personales.

El ambientalista carece de una construcción como personaje. Es más un objeto que representa una idea social que un personaje dramático.

Abigail e Irene son objetos en relación con el contexto social. No se vinculan directamente en este. Respetan lo que dice Vicente en las reuniones y no dicen nada al respecto.
Los personajes no protagónicos establecen relaciones diversas en las acciones. En León, el pulpero famoso de Puerto Viejo (secuencia 7, escenas 1 y 2), encontramos rasgos de chino, no de caribeño. Hay que resaltar que la presencia de chinos en el área es importante a partir de la construcción del ferrocarril en el siglo XIX. No encontramos evidencias de su construcción psicológica. La empatía de León con la audiencia se debe a que su personaje es más documental que ficción. Él es el dueño real de la pulpería y ha sido entrevistado muchas veces por los medios periodísticos nacionales en los últimos años y de ahí su reconocimiento.

Los representantes de la petrolera están débilmente construidos. Uno es tico y otro es mexicano. Su vestuario, acciones y otros atributos aportan poco a la historia. Ellos están a favor de la perforación y eso es todo; no exponen sus causas en la decisión tomada. Son caricaturas diseñadas para que los protagonistas tengan un enemigo concreto en la historia de la perforación petrolera.

En la película casi todos los personajes se sustentan en relaciones con los procesos socio-históricos desarrollados. Vicente es el personaje que se ve más afectado por las condiciones y procesos sociales desarrollados en el film. Su transformación como personaje se justifica por las alteraciones sociales a que está expuesto como dueño de una finca bananera que debe vender y vivir en un paraíso tropical, que en una eventual perforación petrolera, podría verse afectado por la contaminación. 
En el film, la perforación petrolera actúa como catalizadora en los conflictos sentimentales creados en el triangulo amoroso de Vicente con las hermanas. Abigail e Irene son dos personajes que no se ven afectados directamente con la perforación. Ellas no hacen alusión, discuten o se comprometen con causa alguna. No viven el proceso en lo absoluto. Están dormidas en su misma relación externa-interna como personaje. Sus conflictos son de índole sentimental. El estado de equilibrio de ambas está en el orden de las relaciones interpersonales, no en el orden de las relaciones sociales.

El Vecino es el personaje que se compromete en contra de la perforación, pero no evidencia una sola acción al respecto. Cuando le dice a Vicente que desaprueba las acciones de la petrolera solo hace eso, lo dice, no muestra una sola acción física o desencadenante.

La construcción del Ambientalista como personaje es la de servir como vínculo entre los opositores y Vicente. No evoluciona significativamente con el contexto. Sí encontramos una débil evolución en la secuencia donde muestra su rechazo a Vicente por la posición tomada a favor de la petrolera. Lo hace después de haber tomado licor.

Según Birri (1996), el cine latinoamericano se caracteriza por una narrativa que pasa de ser una ficcionalización de un hecho histórico a ser una recreación de un evento histórico concreto.

El film tiene siete secuencias que ahondan en lo histórico o documental. Estas representan el 32\% de las secuencias. Son secuencias que desarrollan ideas comprometidas con los conflictos y problemas sociales propios de la zona atlántica costarricense en el momento histórico que narra la obra audiovisual.

La estructura es el soporte narrativo del film, es el esqueleto donde se acomodan los relatos para ser presentados con coherencia. La estructura narrativa organiza las secuencias y las escenas desde el punto de vista de la segmentación, de la estratificación y define la intención dramatúrgica de la obra.

Según Jiménez (2005), la estructura narrativa de un film puede ser: lineal (simple o intercalada), paralela, inclusiva, inversa o de contrapunto. La estructura de la película es lineal con dos historias que llegan a ser paralelas. El triángulo amoroso se alterna repetidamente con el contenido social determinado por los intentos de llevar a cabo la perforación petrolera y la respuesta que se deriva.

El 68\% de los relatos del film desarrollan contenidos no comprometidos con lo documental. La construcción de la historia de ficción predomina y se inserta en el contexto social del escenario.

Becerra y Sáenz (2010) argumentan que en el nuevo cine latinoamericano la narrativa debe ser reflejo de una forma particular de concebir el mundo. Se debe abordar el personaje como reflejo de la sociedad, de la cultura y de su lugar de procedencia.

La obra recrea cuatro escenas en donde la historia principal del film se comparte con 
espacios de conflictos sociales. La historia de amor entre Vicente, Abigail e Irene, se recrea en espacios o escenarios donde se desarrollan acciones vinculadas a la perforación petrolera o el pronunciamiento popular contra ella. Por tanto, se evidencia una vinculación de las historias privadas con el desarrollo del proceso documental. La relación está determinada por un tipo de montaje paralelo entre lo privado y lo social con el interés de contextualizar e imponer ritmo. Es poca la vinculación que se establece de forma articulada entre ambas desencadenando así nuevos conflictos.

El análisis incluyó los elementos figurativos de la composición visual que determinan una estética de acuerdo con el tema y el manejo escénico. Nos referimos a la composición de índole figurativa que por sus características estéticas tiene gran relación con el tema. El film recrea escenarios que definen la cultura caribeña costarricense abordada con confianza y respeto. Las filmaciones recrean playas, bosques tropicales, la sostenida lluvia, el pueblo, bares, callejones y hasta un carnaval anual.

El film incorpora también en su composición visual elementos de gran significación en la audiencia. Nos referimos a la composición visual icónica que por sus expectativas semiológicas son generadoras de información relevante en la trama central del film. La mirada de Vicente al espejo ante la duda de no saber qué hacer con Irene, la relación de la lluvia con el estado de ánimo del protagonista, los labios de Irene ante el placer sexual, las telarañas que rodea sutilmente la gran mesa del comedor donde se reúne la familia en problemas, entre otras. Todas ellas denotan una labor creativa en el plano fotográfico en búsqueda de la connotación en la audiencia.

La continuidad es el proceso de narrar teniendo presente la ubicación geográfica y lógica de los personajes en el escenario, el manejo temporal, su relación espacial y la claridad en el entendimiento del discurso audiovisual.

Barroso (2003) argumenta que la continuidad de las escenas puede ser desarrollada de tres formas diferentes: real, fílmica y temática. En general, la construcción de los relatos audiovisuales del film está determinada por los diálogos, por lo que su continuidad necesariamente es real.

La obra mantiene las construcciones escénicas de forma simple y con gran economía de recursos. Los elementos decorativos que actúan en las intenciones dramáticas están relacionados con objetos comunes del entorno cultural que se entrelazan para crear una atmósfera adecuada. Los encuentros de Vicente y Abigail en su casa muestran los pocos límites trazados entre los interiores y los exteriores, donde la luz y la vegetación se integran con los diálogos creando ambientes cálidos. Las reuniones comunitarias se desarrollan en ambientes rústicos y cargados de calor humano. El carnaval es un festín que logra alternancia de colores, sonidos, ritmo y buena música caribeña.

El lenguaje audiovisual del film también es expresión de la economía de recursos a la hora de materializar las acciones físicas y dramáticas. No por eso la obra carece de ese denominador estético que enamora. 
La composición de la imagen es realmente bella y no deja lugar a la incomprensión en ningún momento. Cada imagen responde a una intención comunicativa establecida por los diálogos entre los personajes. El cambio de planos se compromete con la búsqueda del ritmo en cada escena pero responde muy poco a la evolución psicológica de los personajes.

\section{Conclusiones}

Caribe es un film construido con base en una estructura narrativa simple. Sus 53 secuencias organizan las acciones coherentemente en un reducido número de escenarios que son utilizados repetidas veces con el fin de economizar recursos. El manejo escénico es adecuado y no se evidencian acciones creativas en búsqueda de una propuesta visual de autor.

El tratamiento dramatúrgico logrado con el final del film rompe los códigos del cine costarricense y se acerca a los protocolos de la dramaturgia latinoamericana. Dramaturgia rebelde y que rompe cánones. $\mathrm{Su}$ final es inesperado y feminista.

El film logró acertar la vinculación de la historia de amor con el proceso social que se desarrolla. El tema que acompaña de fondo a la historia de amor del film es la eminente perforación petrolera en la zona caribeña del país por una compañía extranjera. Perforación que logró tener el apoyo del gobierno y de un gran grupo de empresarios, capitalinos todos, a quienes no les interesaba el verdadero desarrollo de la zona, según el film. La posible perforación consolidó procesos culturales de la zona y vinculó a diferentes grupos de ambientalistas y a defensores de los derechos de las minorías. El proceso quedó plasmado en la obra audiovisual con gran concreción y responsabilidad.

La construcción psicológica y física de los personajes protagónicos en relación con los procesos sociohistóricos no se explotó suficientemente. La poca profundización en el pasado de los personajes principales incidió en la escasa justificación de sus acciones ante cada conflicto.

Todo lo que sabemos por el film es que Vicente heredó la finca y es un amante de la tierra que vende después. Abigail fue producto de un embarazo en la adolescencia de su madre y después, un estorbo. Aunque dice ser amante de todo lo que se mueva, nunca la vemos haciendo nada por ningún animal o por nadie. Irene lo que quiere es alimentar muchas bocas en la mesa. Ser madre. La raza, la belleza y el origen de cada uno no aportan nada en la historia. No son personajes representativos del lugar ni del país.

Los actores: Jorge Perugorría (Vicente) es cubano, Cuca Escribano (Abigail) es española y Maya Zapata (Irene) es mexicana. Interesante combinación de actores que no hacen referencias pasadas o culturales en la obra.

En cuanto a los no protagónicos, ellos sí establecen vínculos de raza y origen con el escenario del conflicto. Los grupos musicales, los que participan en las reuniones y los que caminan por el pueblo sí son representativos. Es el recurso mejor representado en el film y el que incide en la credibilidad de la historia. 
El único personaje protagónico que evoluciona a raíz de los conflictos sociales es Vicente, un personaje construido por oposición y evolución. Todas las acciones las desarrolla con base en las dudas y en las transformaciones que el sistema social le obliga. En el film es una víctima más de la perforación petrolera que ante la incertidumbre de su futuro y su miedo para tomar decisiones en momentos claves, acaba por establecer una relación con su cuñada. Por lo tanto, añora y alcanza el único objeto prohibido en la historia. Abigail es un personaje vacio y poco explotado, que asume ser la víctima durante todo el film sin justificación aparente. Irene es un catalizador.

Los relatos con sentidos completos y las escenas que ahondan en lo histórico o documental son suficientes para mantener esa alternancia entre lo privado-amor con lo público-laboral-social y cautivar a la audiencia con un tema de interés nacional.

El film logra ciertos cambios de movimientos acrecentando el ritmo discursivo y jugando con los cambios de contenidos. Las escenas de las reuniones y las actividades sociales (marchas en Puerto Viejo y Carnaval de Limón) aportan el ritmo y el color de la cultura afrocaribeña en el film, contextualizando y dándole un tinte característico del cine latinoamericano. No caben dudas de que el film es costarricense, filmado en Costa Rica y con una problemática muy nacional.

El film es muy figurativo. Encontramos una estética muy comprometida con el cine documental costarricense con temas ecológicos - ranas, arañas, pájaros, árboles- que lo llenan de belleza pero no de significación. Se abusó de la utilización de estas imágenes sin sentido en la narrativa del film. Estos elementos, nadie puede negar su belleza, se convierten en un ruido semántico en el discurso.

Caribe carece de elementos icónicos en su composición visual. Las imágenes no permiten una connotación profunda debido al mal montaje en referencia a otras situaciones, no por su propia composición. La iconografía se basa en la yuxtaposición, no en el valor de una sola imagen. Resaltamos tres imágenes que alcanzan la iconografía: la tela de araña cuando a Vicente se le complica la vida, los truenos en la noche cuando los problemas están por venir y las dos mujeres en la playa, ya Irene embarazada, que anulan la importancia de Vicente en la vida de ellas.

El montaje es la etapa más precaria en el proceso de realización del film. No sabemos si es un intento de llegar a los 90 minutos insertando planos al azar de los animales de la zona o es un intento de hacer ecológico, llamativo y colorido el film.

La utilización de los escenarios marca la evolución de las acciones físicas y dramáticas. La obra se filmó en los escenarios caribeños que fueron testigos del proceso histórico. Es una producción en términos de géneros que se acerca al docudrama dado el respeto a los escenarios y locaciones del entorno que tuvo su equipo creador.

La construcción escénica fue creada y desarrollada de acuerdo con los elementos decorativos y circunstanciales. Encontramos elementos enriquecedores de la cultura, elementos que determinan la posición 
social de los personajes, elementos naturales y, sobre todo, elementos que justifican las acciones de los personajes.

El film fue realizado con una gran economía de recursos. Las locaciones fueron bien aprovechadas como escenarios y su filmación puede catalogarse correcta y modesta.

En cuanto al uso del lenguaje audiovisual en función del relato, la psicología de los personajes y el conflicto, creemos que es débil. Por momentos, la cámara se enfrasca en la filmación de la belleza sin tener presente las necesidades de comunicar otras cosas, como pueden ser las relaciones entre los personajes, sus intenciones y sus necesidades. La proxemia responde más a la distancia entre los actores en el escenario que a una composición visual para determinar la relación psicológica entre los personajes.

La focalización no es lo fuerte del film. La cámara nunca actuó en función de los personajes, el protagonismo y los conflictos ente ellos. Actuó como una espectadora ingenua que no se dejaba impresionar por el carácter de los diálogos ni por las acciones físicas que se desprendían.

Encontramos escenas, como la primera reunión donde Vicente participa, donde la cámara actúa con subjetividad, acrecentando la intención de focalizar desde la perspectiva interna que no concuerdan con los argumentos expuestos. Los planos subjetivos no son de Vicente y carecen de significados en el relato.

El film Caribe es una obra representativa que, aunque no llega a alcanzar los patrones estéticos, narrativos y visuales de otros films en el continente, es una buena obra para dar a conocer el país, y que debe ser vista y analizada. Es un referente apropiado para abordar determinados acontecimientos históricos relacionados con la perforación petrolera y la forma de abordar y de resolver los problemas sociales desde la perspectiva costarricense.

Escribía José Martí en 1885, “Los hechos legítimamente históricos son tales, que cada uno en sí, a más de reflejar en todo la naturaleza humana, refleja especialmente los caracteres de la época y la nación en que se producen; y dejan de ser fecundos, y aun grandiosos, en cuanto se apartan de su nación y de su época."

Caribe es un buen film de su época y representativo de la cinematografía latinoamericana. Costa Rica necesita otras películas como Caribe en sus salas de cine.

\section{Referencias}

Barroso, J. (2006). Producción Audiovisual. España: Ed. TVE.

Birri, F. (1996). Por un nuevo cine latinoamericano. Madrid: Cátedra / Filmoteca Española.

Becerra Riberos y Sáenz Forero (2010). Las Nuevas Narrativas del Cine Latinoamericano. Colombia.

Delgado, J. y Gutiérrez, J. (2005). Métodos y Técnicas Cualitativas de Investigación en Ciencias Sociales. España. Ed. Síntesis Psicología.

Hernández, R., Fernández, C. y Baptista, P. (2014). Metodología de la investigación. 6 ed. México: Mc Graw-Hill. 
Schroeder, Paul A. (2011). La fase neo barroca del Nuevo Cine Latinoamericano. Revista de Crítica Literaria Latinoamericana, vol. 37, $\mathrm{N}^{\circ} 73$, Lima / Boston, pp. 15-36. 
